\title{
Desafíos de la movilidad electrónica en entornos escolares de la educación infantil
}

\author{
Challenges of Electronic Mobility in School Environments of Early Childhood Education
}

\section{Desafios dos meios eletrônicos em ambientes escolares da educação infantil}

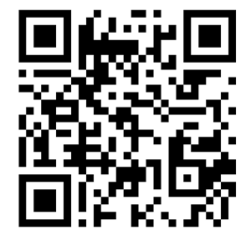

Concepción Sánchez Blanco

Universidad A Coruña

A Coruña, España

concepcion.sanchez.blanco@udc.es

http://orcid.org/0000-0003-1384-3456

Recibido • Received • Recebido: 18 / 06 / 2019
Corregido • Revised • Revisado: 20 / 01 / 2021
Aceptado • Accepted • Aprovado: 14 / 03 / 2021

Resumen: Este ensayo reflexiona sobre un uso crítico de los medios electrónicos y de la movilidad de información que producen, junto con los desafíos educativos que abren en los primeros años de la escolaridad, haciendo especial hincapié en las tecnologías de la información y la comunicación (TIC). Se partirá de la discusión de resultados y conclusiones surgidas a raíz de trabajos de investigación cualitativos realizados por la autora al respecto, durante varios años, entre el 2012 y 2018 en Galicia (España). Se apoyará, también, en el análisis explicativo del papel que juegan estos medios en el mundo social, así como en las necesidades infantiles, del profesorado y, en general, de los entornos escolares, inmersos en un mundo en el cual la movilidad electrónica, azuzada por la celeridad, rompe fronteras temporales y espaciales. La búsqueda de la simultaneidad y la construcción de caminos planetarios han hecho que la información salga y entre y se proyecte fuera y dentro del planeta. Nuevas realidades e identidades emergen capaces de originar no pocas dificultades, pero también nuevos senderos y soluciones a problemas hasta entonces irresolubles. El uso comprometido con la justicia y contra la exclusión de las TIC debiera formar parte de las intervenciones de la escuela, representando recursos y no fines en sí mismas, de manera que su uso ético resulta condición imprescindible para que sean verdaderamente educativas. Han dado lugar a realidades complejas y niños y niñas de cortas edades construyen conocimiento al respecto, por lo cual representan una fuente de prácticas docentes que deben ser analizadas para alejarse de la exclusión y empeñarse en la búsqueda de la equidad, entendida desde el punto de vista infantil.

Palabras claves: Educación infantil; movilidad electrónica; alfabetización digital; tecnologías de la información y la comunicación. 
http://doi.org/10.15359/ree.25-2.27

http://www.una.ac.cr/educare

educare@una.ac.cr

\begin{abstract}
This essay reflects on the critical use of electronic media, the mobility of information they produce, and the educational challenges they pose to the early years of schooling. The paper puts emphasis on information and communication technologies (ICTs). It is based on results and conclusions from qualitative research the author conducted in this regard for several years (20122018) in Galicia (Spain). It is also based on the explanatory analysis of the role played by these media in society and the needs of children, teachers, and in general, school environments. School is immersed in a world where electronic mobility, driven by swiftness, breaks temporal and spatial boundaries. The search for simultaneity and the construction of planetary paths have made the information go in and out and be projected outside and inside the Earth. New realities and identities are emerging and can cause not a few difficulties but also find new ways and solutions to problems that were so far unsolvable. The ICTs use committed to justice and the fight against the exclusion should be part of the school interventions. From the earliest ages, children must have the opportunity to live in environments where such purposes are sought, and their experiences and ideas are heard. Electronic media should represent resources and not ends in themselves so that the ethical use of these is an essential condition for them to be truly educational resources. ICTs have given rise to complex realities in relation to which children of short ages build knowledge. They represent a source of teaching practices that must be analyzed in order to distance themselves from the exclusion and strive to seek equity, understanding the child's point of view.
\end{abstract}

Keywords: Early childhood education; electronic mobility; digital literacy; information and communication technologies.

Resumo: Este ensaio reflete sobre o uso crítico dos meios eletrônicos e o uso das informações que eles produzem, juntamente com os desafios educacionais que proporcionam nos primeiros anos de escolaridade, com especial ênfase nas tecnologias da informação e da comunicação (TIC). Baseia-se na discussão de resultados e conclusões decorrentes de uma pesquisa qualitativa realizada a este respeito por vários anos (2012-2018) na Galiza (Espanha). Também se apoia na análise explicativa do papel desempenhado por esses meios no mundo social, assim como nas necessidades das crianças, professores e, em geral, ambientes escolares imersos em um mundo no qual os meios eletrônicos, impelidos pela velocidade, quebram fronteiras temporais e espaciais. A busca pela simultaneidade e a construção de vias planetárias fez com que as informações saíssem, entrassem e fossem projetadas dentro e fora do planeta. Novas realidades e identidades emergem, capazes de causar dificuldades, mas também novos caminhos e soluções para problemas que antes não eram solucionáveis. $\mathrm{O}$ uso das Tecnologias de Informação e Comunicação, comprometido com a ética e com a justiça, deve fazer parte das intervenções da escola, constituindo-se como recurso e não como fim em si mesmo, de modo que cumpram verdadeiramente os objetivos educacionais. As TIC deram origem a realidades complexas nas quais as crianças constroem conhecimento sobre o assunto e representam uma fonte de práticas de ensino que devem ser analisadas para afastar-se da exclusão e buscar a igualdade, compreendendo o ponto de vista da criança.

Palavras-chave: Educação infantil; meios eletrônicos; alfabetização digital; tecnologias de informação e comunicação. 


\section{Introducción}

Este ensayo reflexiona sobre un uso crítico de los medios electrónicos y de la movilidad de información que producen, junto con los desafíos educativos que abren en los primeros años de la escolaridad, haciendo especial hincapié en las TIC. Da cuenta de aspectos considerados claves para vertebrar los procesos de enseñanza y aprendizaje al respecto. Se partirá de consideraciones surgidas a raíz de trabajos de investigación cualitativos realizados por la autora durante varios años, entre el dos mil doce y dos mil dieciocho en Galicia (España). Concretamente se trata, por un lado, de un estudio de caso realizado en una escuela con niños y niñas de entre tres y seis años; y por otro, de un conjunto de entrevistas abiertas realizadas a niñez de entre cuatro y cinco años de edad.

La movilidad electrónica que acompaña a las TIC, más allá de la movilidad biológica y mecánica (Bericat Alasuey, 2005), constituye una forma de desplazamiento que paulatinamente ha ido conquistando los más diversos contextos sociales de la vida ciudadana. A lo largo de la historia, los seres humanos fueron inventando caminos para transmitir información con un carácter bidireccional. La movilidad electrónica se distingue de la movilidad biológica y mecánica en su misma naturaleza, al trasladar información convertida en micromateria, en el espacio, no personas físicas. La escuela ha de estar preparada para los nuevos retos que se abren. Indagar sobre las consideraciones infantiles, fruto de sus observaciones del mundo, nos descubre el asombro infantil por las prácticas adultas en relación con el uso de las TIC, junto con la información que sostienen y los procesos que se generan al respecto.

Este artículo abordará un análisis explicativo del papel que juegan estos medios en el mundo social, así como de las necesidades y explicaciones infantiles sobre ello, de los desafíos a los cuales se enfrenta el profesorado de la educación de los primeros años en Galicia y, en general, del papel educativo de los entornos escolares, inmersos en un mundo en el cual el traslado de información de todo tipo ha ido ganando en rapidez. Esta movilidad, llamada electrónica por tratarse del traslado de información convertida en micromateria, ha acabado por romper fronteras temporales y espaciales. La búsqueda de la simultaneidad y la construcción de caminos planetarios con la utilización de satélites, de computadoras y de otro tipo de dispositivos cada vez más sofisticados y complejos ha hecho que la información salga y entre, y se proyecte fuera y dentro del planeta.

Si bien cada tipo de movilidad genera su particular espacio, estos se hayan cada vez más interconectados, y hacen emerger nuevas realidades e identidades, capaces de originar no pocas dificultades, pero también nuevos senderos y soluciones a problemas hasta hace poco irresolubles, como, por ejemplo, la comunicación simultánea con personas de diferentes partes del mundo. Espacio biológico o peatonal, espacio mecánico o vehicular y espacio electrónico se entremezclan e indiferencian cada vez más (Bericat Alasuey, 2005). Podemos poner un ejemplo como el siguiente. Las personas se pueden desplazar biológicamente pertrechados de aparatos 
http://doi.org/10.15359/ree.25-2.27

http://www.una.ac.cr/educare

educare@una.ac.cr

electrónicos utilizándolos simultáneamente para acceder a información de muy diferente tipo y conectarse con personas diversas, pudiendo originar no pocos accidentes de tránsito; pero también, contradictoriamente, mayores posibilidades de prevención de siniestros relacionados con la movilidad, una mayor supervivencia y calidad de vida. Desde muy tempranas edades, cada vez más niños y niñas penetran en este entramado contradictorio a través de los teléfonos móviles por mediación de las personas adultas, y ponen en riesgo su seguridad o, por el contrario, la salvaguardan. Al observar atentamente las prácticas de sus mayores, abierta o encubiertamente, esto les van sumergiendo en valores relativos el uso de las TIC.

Escuchar las voces infantiles, observando juegos y escuchando discursos desde las más tempranas edades, se convierte en una necesidad porque facilita la autocrítica por parte del mundo adulto de sus propias prácticas. Ofrecerles contextos de participación a niños y niñas en los entornos escolares se convierten en esencial, pues además de desvelar los valores implícitos en nuestras acciones adultas, contribuirá a deshacer esas fronteras que impiden que puedan trascender una posición de meros sujetos consumidores de medios electrónicos, navegando sin conciencia por sus contenidos, principalmente, por aquellos diseñados por las multinacionales del ocio y el entretenimiento. Se impone, así, que la escuela se comprometa a incluirles en una movilidad electrónica liberadora que les sitúa como personas críticas, creadoras y verdaderas protagonistas en cuanto a la utilización de TIC.

\section{Desarrollo}

La escuela no solo se enfrenta a la falta de acceso a las TIC de las infancias más pobres; también se enfrenta a ciertos excesos y usos indeseables que, contradictoriamente, vienen a empobrecerla socialmente $y$, por ende, al mundo. Hay procesos de alienación y adoctrinamiento que surgen producto de un acceso y uso indiscriminado de niñas y niños a los medios electrónicos. Las adicciones y una evasión patológica de la realidad, junto con las noticias falsas, pueden estar a la vuela de la esquina, y afectan tanto a personas adultas como a niños y niñas desde las edades más tempranas, cuando se produce un consumo compulsivo y alienante de información. Las personas adictas al móvil, a las redes sociales, tecnoadictas o ciberyonkis existen y requieren de programas terapéuticos hospitalarios y grupos de ayuda para enfrentar este tipo de adicciones, que acaban por dar al traste con la vida y la economía de los sujetos y que comenzaron a gestarse en algún momento de sus vidas. En el mismo informe de la United Nations International Children's Fund (Unicef, 2017) Estado mundial de la infancia. Niños en un mundo digital no solo se apunta la necesidad de aprovechar las oportunidades que ofrece la era digital para favorecer a toda la población infantil, ahuyentado cualquier tipo de exclusión; sino también se demanda la necesidad de destinar recursos concretos y de cooperar para que todos y todas reciban protección, de manera que no se dañen por esas otras consecuencias indeseables que se derivan de un mundo más conectado. 
Desde las edades más tempranas, la escuela ha de asumir la responsabilidad de trabajar con sus escolares para que adquieran normas de uso saludables de las TIC. Los propios adultos y adultas, docentes y familiares deberían reflexionar sobre su propio comportamiento al respecto, especialmente de aquel relacionado con las redes sociales pobladas de personas e ideologías diversas, máxime si tenemos en cuenta que la niñez está aprendiendo de estos modelos de prácticas que les ofrecen las personas adultas, especialmente, las más cercanas y significativas (Sánchez Blanco, 2018). Las técnicas de control parental en relación con el uso de los medios electrónicos resultan, a todas luces, insuficientes e, incluso, ineficaces, y pueden ser regateadas (Marsh, 2004), como muestran, alarmantemente, por ejemplo, los trabajos sobre el acceso a pornografía, por parte de las personas menores en España. Por lo tanto, lo más importante es contribuir con la educación a que, desde las edades más tempranas, aprendan a hacer un uso responsable de los medios electrónicos.

La escuela puede y debe trabajar para enfrentar este tipo de situaciones y otras donde las TIC se han convertido en herramientas para traspasar la legalidad y la moralidad, atentando contra los derechos de las personas entre ellos los de la niñez. Por ello es urgente que, desde las edades más tempranas, a las personas escolares se les ponga en situación de aprender a apropiarse de la tecnología asociada a la movilidad electrónica, entre otras razones, para usarla, tanto en beneficio propio como colectivo, en aras del bien común. Las TIC generan espacios que hay que ocupar y en los que hay que luchar para que las formas de democracia sean más profundas (Pisani y Piotet, 2009). La misma situación desoladora de pandemia mundial ha develado el poder de las TIC dentro y fuera de las escuelas, pero también los procesos de exclusión que un uso sesgado e injusto de estas mismas puede producir entre la niñez $y$, en general, en toda la población de un país como el caso de España.

\section{Discusión}

\section{El marco social: De la voracidad a la frugalidad}

Necesitamos una escuela rica en experiencias donde la utilización de las TIC sea analizada, discutida y deconstruida, más allá del mero aprendizaje de la herramienta. De lo contrario, los medios electrónicos habrán llegado, no para enriquecer la educación, sino para empobrecerla y ponerla en peligro. Si la accesibilidad necesaria a las TIC viene marcada por el estatus socioeconómico de las personas, como ha venido sucediendo con la movilidad mecánica, estaríamos marginando a los sujetos con menos recursos -brecha digital- (de BenitoCastanedo, 2017), máxime si con ello se les priva del conocimiento necesario para desarrollar las capacidades que se derivan de la propia condición de humanidad (Nussbaum, 2001) y la construcción de redes de indignación contra la injusticia y su denuncia (Castells, 2012). 
http://doi.org/10.15359/ree.25-2.27

http://www.una.ac.cr/educare

educare@una.ac.cr

Sin embargo, el consumo individualista y exacerbado de estos materiales no hace sino generar una sobre explotación de los recursos del planeta, así como elevar la cantidad de residuos producidos, dando como consecuencia importantes problemas medioambientales. Frente a esta situación relatada, defendemos, por el contrario, asumir el desafío de un uso compartido de esta tecnología que vaya contra ese despilfarro y la proliferación de basura electrónica (Hidalgo Aguilera, 2010), haciendo que la equidad en cuanto al uso de aparatos electrónicos y la sostenibilidad caminen de la mano. La propia escuela debiera ser un referente al respecto. Ello implica huir de modelos centrados en la tecnología, para vertebrarlos sobre el aprendizaje. Aspirar a un uso individualizado de aparatos electrónicos como el móvil o la computadora representa, por lo tanto, un atropello para el planeta que, como no pongamos remedio, se nos muere irremediablemente.

Se trata de instalarse en un ecologismo de las personas pobres que se ampara en la justicia ecológica (Martínez Alier, 2005). Generar espacios de uso compartido de TIC, potenciarlos e impulsarlos es una medida bien necesaria, como ya venimos haciendo con otro tipo de tecnología como las lavanderías colectivas gestionadas de forma cooperativa y compartida en bloques de viviendas, De esta forma, una de las grandes cuestiones en la que ha de ocuparse la escuela es cómo hemos de manejar esta movilidad electrónica, desde las edades más tempranas, para que pueda convertirse en elemento esencial, no solo para luchar contra la marginación, también para incorporar en su utilización valores como la frugalidad, el ahorro y, por ende, la sostenibilidad, y alejarnos de caminos gobernados por la opulencia, el hiperconsumo y el despilfarro. No olvidemos que los valores economicistas dibujan fronteras que la escuela ha de saltar, comprometiéndose con el bien común y, por lo tanto, con un uso compartido de los recursos. La tecnología low-cost de países pobres que salva vidas en países ricos representa una lección para ese otro mundo que ha hecho de tirar, comprary tirar su máxima.

Democratizar el acceso a la información veraz y activar procesos educativos capaces de transformarla en conocimiento compartido que nos haga más libres, ese debiera ser otro propósito esencial, pero solo será posible si asumimos el reto de plantar cara a un hiperconsumo per se de cachivaches electrónicos e información ruido que oprime y convierte a los seres humanos en meros objetos manipulados y subyugados. Dice Han (2017) que, a partir de determinado momento, la información ya no es informativa, sino deformadora; la comunicación ya no es comunicativa, sino meramente acumulativa. El conocimiento es redención; sin embargo, la mera información carece de la dimensión de alteridad. Hoy la red se transforma en una caja de resonancia especial, en una cámara de eco de la que se ha eliminado toda alteridad, apunta este filósofo coreano. La gula informativa nos enferma; el saber, el conocimiento nos conforta y nos reconcilia con el género humano. Frente al mero consumismo de información, es la construcción de conocimiento y sabiduría, a partir de las experiencias vividas con las otras personas, utilizando, llegado el caso, el apoyo de los medios electrónicos, el propósito que debiera guiar las prácticas docentes. 


\section{Miradas infantiles y educación en medios: Profundidad versus superficialidad}

Las TIC pueden facilitar la vida de los seres humanos favoreciendo la inclusión de niños y niñas en la escolaridad desde las edades más tempranas, así como la prevención y ruptura de procesos de exclusión, si las utilizamos como efectivas herramientas de comunicación, y convertimos las instituciones escolares - sean del tipo que sean, atiendan la población que atiendan, se localicen donde se localicen- en verdaderas comunidades críticas de aprendizaje, donde la lucha contra la exclusión y la construcción de democracia constituyan principios de acción fundamentales, así como la ruptura de procesos de aislamiento, por lo tanto, organizadas con un marcado carácter universal, sin fronteras. Sin embargo, no hemos de olvidar, como venimos apuntando, que en el fenómeno de la movilidad electrónica se enredan también asuntos tan trascendentales como el clasismo, el maltrato, la alienación o el despilfarro, que enturbian y deshacen las relaciones humanas, y dan lugar a otro tipo de pobreza digital, sembradora de injusticia, que va más allá de tener o no tener esta tecnología o estar desfasada. En este caso se trata de criticar los valores que rodean su uso. Por lo tanto, hemos de trascender esa visión idílica, exclusiva, de la cultura digital, de internet, como espacio público donde la humanidad puede compartir su conocimiento, cuando sabemos, fehacientemente, que poderosas multinacionales con importantes intereses económicos nos acechan, con el propósito de adueñarse de nuestra actividad, de nuestros datos, tratando de contralar nuestras vidas en su beneficio. Desafiar esa visión idílica implica organizar acciones de resistencia destinadas a denunciar los atropellos de las corporaciones económicas que trafican con la vida electrónica, acciones con las cuales los entornos escolares, con todos sus miembros, han de comprometerse. Resulta totalmente contradictorio, como reflexiona Lanier (2018), que, en aras de la búsqueda de la comunicación entre personas, hayamos construido una sociedad en la cual el camino para lograrlo requiera de un intermediario que persigue manipularlas con el afán de hacer negocio y lucrarse a costa de la mercantilización de los sentimientos.

No podemos permitir que las ficciones de todas esas redes sociales virtuales se adueñen de las escuelas, de sus alumnos y alumnas, de sus docentes, de sus familias. Así, profesorado con canales de youtube y blogs ofreciendo soluciones simples a problemas complejos de niños y niñas de edad temprana y actividades de dudoso valor educativo no deberían existir. Pero, además, ni el profesorado puede ser reducido a la condición de influencers, ni el alumnado y las familias a la de folowers. La educación, no olvidemos, persigue la liberación, como recoge Freire (1970), no el entretenimiento.

El nomadismo electrónico puede apoderarse de los sujetos hasta destrozar su existencia. Puede transformar la vida virtual en más importante que la vida real hasta, incluso, confundir y convertir a las personas en consumidoras compulsivas de las supuestas oportunidades que estos medios ofrecen. Desbordarse por los deseos insatisfechos que publicitan los medios electrónicos (Klein, 2011) -ni qué decir-tiene, empobrece la existencia humana hasta extremos 
http://doi.org/10.15359/ree.25-2.27

http://www.una.ac.cr/educare

educare@una.ac.cr

insospechados. Y aquí no podemos olvidar el peso de la publicidad, hábilmente diseñada para enganchar a niños y niñas desde muy pronto, y a sujetos adultos, una publicidad hecha a la carta que circula por la red, vendiendo de forma certera al aprovechar los rastros informativos que los sujetos dejan conforme se mueven por ella al hacer uso de sus contenidos. La escuela ha de desafiar este tipo de contenidos comprometiéndose con el desarrollo del alumnado como consumidor crítico.

Niños y niñas desde las edades más tempranas han de aprender a vivir de forma emancipada en un contexto donde los medios electrónicos pueden tanto liberar como dominar, imponiendo unas formas de vida frente a la minusvaloración y denigrado de otras, al amparo de no pocos prejuicios, injusticias y procesos excluyentes. Procesos de colonización de conciencias de diferente calado pueden invadir contenidos electrónicos de todo tipo, extendiendo hegemonías y procesos de dominación y discriminación desde las más tempranas edades. De ahí, la importancia de la escuela para realizar selecciones verdaderamente valiosas de contenidos y de medios, previniendo y cuestionando tales situaciones, convirtiendo a los escolares y las escolares en ciudadanía que salta las fronteras de los localismos, construyéndose como cosmopolita, responsable, crítica, juiciosa, en el uso de los medios electrónicos, desde las más cortas edades.

Entendemos que el logro de tales propósitos debería ayudarse, entre otras medidas, por un lado, de la investigación de las experiencias y las percepciones infantiles acerca de las TIC y la construcción de conocimiento que niños y niñas hacen al respecto; y por otro, del análisis de contenidos que se les ofrecen a las infancias a través de las diferentes pantallas, que imponen como necesaria y urgente una alfabetización digital en medios en la escuela (Buckinham, 2008). Estos dos caminos nos llevan, inevitablemente, a la necesidad de descubrir ese asombroso mundo que están construyendo las infancias de diferentes contextos sobre los medios, digno de ser conocido, escuchado y analizado. Dado que, como señala Gopnik (2010), son capaces de desarrollar procesos investigativos y reflexivos tan extraordinarios, que han llegado a captar la atención de los científicos para enriquecer sus métodos de estudio, practicar la escucha atenta malaguzziana de las consideraciones infantiles se impone como esencial. Nos hará reflexionar sobre nuestras intervenciones adultas, al buscar en la escuela nuevas rutas para transitar utilizando la movilidad electrónica, con capacidad de contribuir a que la riqueza que pueden traer los medios electrónicos, no acabe convertida, a la larga, en pobreza social.

Educar en medios electrónicos exige saber el modo en que la infancia de diferentes edades y de diferentes partes del mundo puede estar construyendo conocimientos al respecto; así como de qué manera se desarrolla su comprensión a lo largo del tiempo. Además, no podemos perder de vista que los medios electrónicos no se limitan solo a reflejar el mundo, porque también transmiten representaciones de este mismo, con sus luces y sus sombras (Buckingham, 2008). Esta situación convierte en más necesario, si cabe, la necesidad de 
indagar acerca de cómo pueden estar influyendo los contenidos que difunden tales medios entre la niñez desde las edades más tempranas. Todo ello nos obliga a que el profesorado esté necesitado del reconocimiento de la diversidad social de alfabetizaciones que se producen en torno a las TIC y que se viene produciendo en las infancias desde las más cortas edades; así como, de las funciones sociales que desempeñan. Comprometerse con este reto es necesario a fin de conocer cómo el uso de estas tecnologías en las familias puede estar afectando de forma diferente a los escolares y a las escolares en su desarrollo, antídoto necesario contra la pobreza social y los procesos excluyentes.

Entrevistas realizadas por la autora en Galicia (España), a raíz de dibujos infantiles pedidos para sus investigaciones, nos muestran el asombroso mundo que los niños y las niñas construyen alrededor de artefactos, como es el caso de los ordenadores; y que nos ponen de manifiesto el poder infantil para plantearse hipótesis sobre las TIC. Cada vez son más los niños y las niñas y de edades más tempranas, que tienen experiencia, sino como público usuario, al menos en un rol de observación de otros sujetos usuarios de artilugios electrónicos como, por ejemplo, los ordenadores, las tablets y los móviles, en casa y en las escuelas. También, a diario, pueden contemplar cómo se utilizan estos en otros espacios diferentes. Xosé (4años), por ejemplo, se dibuja con el ordenador como un doctor escribiendo: el niño está enfermo, se tiene que quedar en el médico y tomar un jarabe. Observar el juego simbólico de los pequeños y las pequeñas nos acerca también a sus consideraciones sobre los medios electrónicos y su relación con los contenidos creados para ello, como Clara (5años), que subida en un triciclo con un teléfono de juguete dice: Cortana, quiero ir a Pontevedra.

En cuanto a los contenidos, Uxía (4años) cuenta que Pepa Pig tiene un ordenador y que juega a la gallina feliz. Repasando capítulos de esta serie, llaman la atención situaciones como la que se describe a continuación: Pepa le pregunta a mamá si la pueden ayudar en su trabajo y se pone a tocar el teclado del aparato de forma indiscriminada. Mamá, ante el comportamiento de su hija, le dice a ella y a su hermano George, que no deben tocar la computadora. Asimismo, cuando juegan a la gallina feliz con su papá, es este el que introduce el disket del juego dentro del ordenador y no Pepa y su hermano. Se les reprende o ignora, cuando tratan de manipular el aparato, conforme al prejuicio de que los niños y las niñas pequeños estropean todo lo que tocan. Son también conscientes de que las computadoras cuestan dinero y son caras. Hugo (4años), refiriéndose a este aparato afirma: cuesta por lo menos cien euros (que para él es mucho). Xurxo (4años) señala: el ordenador cuesta y hay que dejar dinero a los señores. Es además consciente de la necesidad de no despilfarrar, manifestando, asombrado, con toda lógica, que un ordenador no se puede comprar con un ordenador porque para que vas a comprar un ordenador con un ordenador si ya tienes un ordenador.

Estos discursos y producciones infantiles constituyen una muestra de algunas de las hipótesis tan potentes que la autora descubrió en las conversaciones mantenidas con los 
http://doi.org/10.15359/ree.25-2.27

http://www.una.ac.cr/educare

educare@una.ac.cr

escolares de entre cuatro y cinco años en una escuela gallega y que nos ofrecen pistas acerca de hechos sobre los medios electrónicos que merecería la pena discutir con la infancia (SánchezBlanco, 2017). Pero, además, proponemos desarrollar en las escuelas una especie de metareflexión, que permita a las infancias deliberar sobre los discursos que los propios medios electrónicos hacen de ellos mismos como infancia. La escuela ha de asumir el desafío de facilitar a la niñez experiencias que consideren las hipótesis infantiles como punto de partida, en las cuales se haga un uso ético, liberador, comprometido de los medios electrónicos. Una praxis liberadora en alfabetización digital surgirá en un marco donde el personal docente tiene en cuenta la voz de los niños y las niñas, sus conocimientos, hipótesis y valores que construye alrededor de estos. Es esta una alfabetización digital sustentada sobre pilares que mucho tienen que ver con las propuestas freireanas (Freire, 1970) de alfabetización, en relación con la escritura y la lectura de las personas adultas; y que, fundamentalmente, están destinadas a la liberación de las situaciones de opresión de los seres humanos.

\section{Medios de comunicación, contenidos y participación infantil}

No podemos eludir el análisis crítico de los contenidos a los cuales tiene acceso la niñez a través de las múltiples pantallas. El sexismo, el racismo, la xenofobia y todo tipo de estereotipos y prejuicios muy bien pueden estar acompañando, de forma solapada, las imágenes, mensajes y contenidos; llega, incluso, a través de la misma publicidad que los acompaña, a promocionarse productos y marcas de dudoso calado ético. Con los relatos de los medios electrónicos, sigue pasando lo mismo. Además, nos encontramos con que todo tipo de merchandising viene a reafirmar, bien a menudo, todos esos valores criticables que destilan los personajes creados, para el consumo infantil, por las multinacionales del ocio y entretenimiento. Las imágenes y los discursos circulan a velocidad de vértigo, fotograma, tras fotograma, convirtiendo en un imposible su análisis y discusión in situ. La velocidad misma se convierte, así, para niños y niñas, en natural, alrededor de la cual se ha fraguado un lucrativo mercado de máquinas de aceleración de todo tipo (Sánchez Blanco, 2013). Una narrativa que tiene como argumento la velocidad y que reaparece en los mismos juegos infantiles, si no intervenimos, acabará convertida en central, a medida que avanzamos en edad.

El movimiento constante, virtual o real, y la velocidad asociada a este constituye uno de los males que nos aquejan; el primero exacerbado y el último, no olvidemos, sometido a controles y restricciones cambiantes en estos tiempos de pandemia. Internet se ha convertido en una de las principales máquinas de aceleración, vulnera, a menudo, los deseos y necesidades de quietud y de permanecer en nuestro lugar de origen rodeado de nuestra gente. El derecho a la quietud plantea no pocos dilemas, pues se da de bruces con la sociedad neoliberal que hemos construido donde el más deprisa, mejor se instala como pensamiento hegemónico. Ese más deprisa, mejor representa una violencia estructural que contribuye a la muerte de la humanidad como resultado de sus productos-consecuencias: la vida acelerada, el exceso de velocidad en la 
carretera, el calentamiento global del planeta, la insalubridad de la comida rápida, el despilfarro, la ingente cantidad de desechos que generamos -entre ellos la basura electrónica- y un marco escolar preocupante que, con su turboacademicismo, meritocracia y competitividad, arropado por las múltiples pantallas, refuerza y genera no pocas patologías desde las más tempranas edades. Los medios electrónicos debieran servir más bien para luchar contra este modus vivendi, y vivir las cosas importantes de la existencia con tranquilidad y sosiego, disfrutando, recreándose (Honoré, 2008), que no para alimentarlo sin fin. La escuela, desde los primeros años, debería involucrarse en el reto de construir experiencias valiosas y ambientes de aprendizajes asociados con la lentitud y donde las TIC tienen cabida.

Perseguimos potenciar desde la escolaridad temprana, que niños y niñas se apropien de las TIC y las utilicen de forma liberadora, situación que permitirá a los maestros y las maestras, al trabajar con la infancia, apropiarse también de aquellas. Los relatos difundidos a través de los más diversos medios a lo largo de la historia han sido utilizados para colonizar, pero también para denunciar, reivindicar, deslegitimar y liberar. Es en esta potencialidad donde se debe apoyar la educación para desactivar el binomio masa domesticación y en la cual ha de ser educada la infancia.

La escuela ha de trabajar para enfrentar ese niño sumergido en un mundo almibarado, alienante, sesgado, construido de espaldas a las desgracias y avatares del mundo real, donde los mismos medios electrónicos pueden ser poderosos instrumentos para alentar y fortalecer procesos de evasión. Sin embargo, estos mismos medios pueden convertirse en herramientas poderosas para los escenarios escolares cuando los maestros y las maestras los utilizan para sumergir a su alumnado en la vida misma, haciendo de ellos sujetos menos localistas y más cosmopolitas. Al conocer las situaciones de otros niños y niñas en el mundo, pueden ir generándose en ellos y ellas procesos de concienciación que les impulse a actuar de forma crítica, cuestionar autoridades, situaciones, prejuicios y, en general, acontecimientos de todo tipo (Robinson et al., 2019), trascendiendo posiciones coloniales (de Sousa Santos y Meneses, 2014) anuladoras de identidades infantiles, como ese colonialismo de mercado que nos azota a grandes y pequeños, al que hay que plantar cara usando las TIC.

Si bien las múltiples pantallas e internet no surgieron con la intención de liberar a la ciudadanía de situaciones de opresión, sin embargo, pueden ser excelentes recursos emancipadores que contribuyan a dar jaque mate a un ethos infantil depredador de recursos (Giroux, 2003) y consumidor de imágenes conforme a las necesidades del mercado. Los avances tecnológicos, por un lado, han llegado a complicar la construcción de procesos de toma de conciencia en las infancias al favorecer la confusión de lo real con lo virtual (Pérez Tornero, 2008), pero también permiten deshacer alienantes confusiones. Valga, como ejemplo, el caso de aquella niñez de cuatro años que estaba convencida de la existencia de Spiderman porque habían visto a este personaje en el ordenador. Además, las imágenes en 3D de un juego venían a fortalecer esta confusión, hasta el punto de pensar que les socorrería cuando estuvieran en peligro. La maestra hubo de intervenir generando un ambiente de aprendizaje donde niños y 
http://doi.org/10.15359/ree.25-2.27

http://www.una.ac.cr/educare

educare@una.ac.cr

niñas tuvieran la oportunidad de contrastar sus creencias. Utilizando los propios medios que promovían la confusión lograría deshacer tales concepciones. Sería, así, necesaria, la fabricación de hologramas, a partir de un taller de tecnología desarrollado en el aula, con objeto de someter a cuestionamiento la realidad o falsedad de las imágenes de este superhéroe.

No olvidemos, además, cómo con el auxilio de las TIC, los negocios de las multinacionales del entretenimiento persiguen que las infancias, convertidas en audiencias de sus espectáculos, se involucren en estos mismos, para lo cual desarrollan patrones de consumo, modelos de juego y filiaciones que acaben por transformarlas en maestras de su vida. Dicen Steinberg y Kincheloe (2000) que la pedagogía cultural de las corporaciones ha hecho sus deberes; ha producido formas de adiestramiento que tienen un éxito enorme cuando se juzga sobre la base de su propósito capitalista.

Las cada vez más poderosas multinacionales del ocio y el entretenimiento, asentadas sobre potentes emporios económicos, con el extraordinario aliado de la publicidad, han contribuido a configurar en gran medida un nuevo ethos escolar, al inocular sus discursos e imágenes en los niños y las niñas, haciendo emerger en aulas y patios de recreo todo un elenco de narrativas que hacen más compleja la vida en la escuela, hasta tal punto que cada vez resulta más difícil desentrañar los significados de juegos y discursos infantiles (Buckingham, 2002; Sánchez Blanco, 2013; Steinberg y Kincheloe, 2000). Tenemos que estar atentos a las narrativas que, a través de los más variados medios, se difunden entre niños y niñas generando toda una mezcolanza que da lugar a una cultura popular que ha de ser comprendida y explicada para poder generar procesos educativos capaces de hacer frente a sus afanes de colonización económica. Estos, en ningún momento, aparcan en la escuela los aprendizajes producidos al reconstruir la narrativa hallada en sus incursiones en las multinacionales del entretenimiento y su publicidad, por más que alguno parte de docente se empeñe, ilusamente, en echar fuera de la escuela todo este mundo.

Sabemos que su conocimiento por parte del personal docente le ayudaría a entender y explicar todo ese universo que niños y niñas llevan a la escuela; sin embargo, no faltan las ocasiones en las cuales los escolares y las escolares se ven obligados a ocultarlo o disfrazarlo, especialmente si, en lugar de ser asumido como reto, es censurado o está desacreditado en las aulas. Hay historias increíbles de vehículos fantásticos, reinos mágicos enredados en mil y un entuertos de todo tipo y conflictos que a menudo se resuelven por la fuerza, personajes, héroes y heroínas diversos, protagonistas de tales historias, realidades virtuales más y menos complejas que se pueden vivir como reales; historias, en definitiva, inventadas por otros entes que han cautivado a la infancia, a su familia y que se extienden a la misma publicidad de juguetes de todo tipo. Con un consumo sin cortapisas y sin capacidad de crítica, corren el riesgo de convertirse en estupendos aliados para la difusión de valores bien útiles para la sociedad hiperconsumista en la que estamos inmersos e inmersas (Sánchez Blanco, 2013).

El cine, las series televisivas, los videojuegos, la misma publicidad de juguetes, los mismos artefactos electrónicos de todo tipo o cualquier otro producto presentado a través de las 
más diversas pantallas para las infancias, quedan muchas veces encarcelados como marcas e ideologías de mercado para consumir (Klein, 2011; Steinberg y Kincheloe, 2000). La educación de los primeros años tiene un reto muy importante ante sí en la transformación de todos estos recursos electrónicos en educativos que potencien el papel activo de niños y niñas como constructores y constructoras de conocimiento de estas tecnologías y con estas tecnologías (Buckingham, 2008, 2013; Tobin, 2004), protagonistas indiscutibles de un mundo acelerado, líquido (Bauman, 2007), donde los cambios se suceden a velocidad de vértigo.

Sin embargo, a pesar de la fuerza de todos estos mensajes, las infancias siguen teniendo ese poder de reconstruir los discursos, las narrativas, poder que la escuela ha de rescatar a través, no solo de propuestas de análisis crítico de sus programas, películas, juguetes y anuncios favoritos, sino también acompañado de una producción creativa de sus propios mensajes construidos con los recursos más diversos, con la finalidad de que den lugar a visiones nuevas y más profundamente críticas del mundo donde viven. La posibilidad de acceder a recursos electrónicos de forma compartida como apps y otras aplicaciones para crear historias; la utilización bajo planteamientos éticos de estos recursos electrónicos, así como la difusión de las producciones infantiles colectivas con afanes de mejora, en las redes sociales, manejadas educativamente, resultan imprescindibles para romper con fronteras que impone un uso segado e individualista de los medios.

Hemos de reconocer que los mensajes, que los textos mismos pueden leerse de muchas formas diferentes, como apunta Buckingham (2008), y que estas diferencias no deberían silenciarse o suprimirse en la escuela, sino, al contrario, tendrían que constituir el punto de partida de los debates que con los niños y las niñas desarrollamos en las aulas. Tomando este presupuesto como comienzo, trabajaremos para que comprendan que detrás de sus respuestas personales en el análisis de estos mensajes están presentes contextos sociales, culturales e institucionales, cuya influencia en sus respuestas han de descubrir. Ser sujeto crítico va, por lo tanto, mucho más allá de una práctica meramente cognitiva.

Entre otros escollos que conviene salvar se encuentran los contras neurológicos capaces de producir las TIC, a los que se refiere Carr (2018), que pueden empobrecer a las infancias. Este autor nos lanza avisos acerca de cómo el uso de los medios electrónicos puede venir a torpedear todo este tipo de loables propósitos educativos que venimos desgranando. Se refiere a las pérdidas y las ganancias a nivel cerebral que se producen; apunta que, si bien internet nos hace ganar en capacidad para la multitarea, también nos hace perder capacidad de reflexión, concentración y atención profunda, asunto este bien impactante que debería hacernos analizar cómo podemos estar condicionando el futuro de la niñez. Las investigaciones se refieren también al sendentarismo (Camargo y Orozco, 2013) y a las escapadas alienantes del mundo real que provocan, produciendo vidas ficticias y amigos virtuales a la carta, antesala de identidades poliédricas de las que la infancia tiene que aprender a protegerse, pues les ponen, como afirma Lanier (2018), en manos de macroempresas tecnológicas a través de estudiados procesos de 
http://doi.org/10.15359/ree.25-2.27

http://www.una.ac.cr/educare

educare@una.ac.cr

modificación de conducta, que vulneran los derechos de la niñez (Sánchez-Blanco, 2016); así que no es por casualidad que los ejecutivos y las ejecutivas de potentes industrias tecnológicas, de Silicon Valley, prefieran que sus más pequeños y pequeñas acudan a escuelas sin conexión a la red (Lanier, 2018). Illouz (2012) afirma que internet contribuye a fortalecer la posición del individuo como sujeto que desea, que anhela ciertas experiencias, ambientes, que fantasea con diversos objetos o estilos de vida, y que vive a su vez en un universo imaginario y virtual. Sin embargo, pese a todo lo dicho, hemos de decir que, pensando en la escuela, el problema no está tanto en los medios electrónicos, sino en la forma que tiene de utilizarlos. Desarrollar caminos que con la presencia de las TIC acerque a los niños y las niñas de los primeros años a la realidad en lugar de aislarles de esta es, sin lugar a dudas, un desafío.

\section{Conclusiones}

Después de todo los desgranado anteriormente nos queda recapitular y apostillar aún más, si cabe, algunos de los aspectos que nos parecen más relevantes. Así, hemos visto que un reto esencial que tiene la escuela por delante, en relación con la movilidad electrónica y con las TIC es la creación de ambientes de aprendizaje capaces de potenciar que niños y niñas, desde las edades más tempranas, se apropien de los medios y los utilicen de forma liberadora, situación esta que permitirá a los maestros y las maestras, al trabajar con ellos y ellas, empoderarse también. Los relatos difundidos a través de los más diversos medios a lo largo de la historia han sido utilizados para colonizar, pero también para denunciar, reivindicar, deslegitimar y liberar. Con los medios electrónicos no puede ser de otra manera en la escuela. Es en esta potencialidad donde se debe apoyar la educación para desactivar el binomio masa domesticación, ahondando, por el contrario, en el derecho de la niñez a ser reconocida en su individualidad y en sus particulares necesidades.

Si, como afirma Pérez Tornero (2008), "la multiplicación de la información y el entorno multipantalla pueden estar creando una saturación para la mente y los sentidos, y estar conduciendo en ocasiones a una especie de embotamiento perceptivo que lejos de ayudar al aprendizaje, sería una barrera para su desarrollo" (p. 21), deberíamos estar especialmente con gran preocupación en el caso de la infancia. Contradictoriamente, como apunta este autor, la misma tecnología permite detener las imágenes y discursos con una mayor profundidad y deshacer manipulaciones.

Hemos de afanarnos en ofrecer a niñas y niños experiencias valiosas de búsqueda de información contrastada, veraz, mostrándoles el poder de las TIC para ampliar horizontes y hacer más complejo su pensamiento. Por lo tanto, convendría no perder de vista las narraciones que hacen los medios de comunicación de los hechos del mundo.

Estas narraciones les llegan a niños y niñas por los más diversos canales. Resultaría un despropósito aislar a la infancia metiéndola en una especie de azucarero al margen de un mundo real que está muy lejos de ser ese lugar apacible y maravilloso (Sánchez Blanco, 2018). De ahí que los medios que sustentan la difusión de acontecimientos que tienen lugar en el 
mundo, desde los más local a lo más global han de entrar a la escuela desde las edades más tempranas. Las TIC pueden convertirse en un extraordinario aliado. Especialmente interesantes resultan, como venimos diciendo, todo aquello que acontece con niños y niñas del mundo, al tratarse de iguales, que facilitan la aparición de sentimientos de empatía que desemboquen en una visión de ciudadanía mundial.

Pueden servir para potenciar una conciencia del mundo asentada sobre el valor de la diversidad, pero también pueden ser utilizadas para sostener formas de hacer y de pensar únicas, excluyentes, al servicio de los intereses de poderosas corporaciones económicas. Este segundo camino nos situaría al borde del precipicio como humanidad y, por ello, se impone el desafío de no rendir pleitesía a los emporios digitales, estableciendo fronteras, limites, que no se pueden traspasar en cuanto al uso de estas mismas. Un consumo de las TIC sin límites éticos por parte de las personas adultas generaría modelos de acción perniciosos para el crecimiento de niños y niñas desde las edades más tempranas.

Solo cabe reiterar un último desafío, que no basta con desarrollar la crítica en torno a los contenidos que afloran en las más diversas pantallas y prácticas en relación con las TIC en las escuelas. Hay también una necesidad de poner a las infancias, desde las edades más tempranas, en situaciones capaces de darles poder sobre sus acciones y en las cuales tengan papeles de activas constructoras de contenidos que hagan que sus hipótesis y conocimientos sobre los medios electrónicos vayan ganando en complejidad, incluidos los relativos a los mismos aparatos que los sustentan. Niños y niñas se muestran, desde muy pronto, con interés acerca de cómo funciona todo tipo de cachivaches tecnológicos, incluidas las TIC. Y esa misma tecnología puede utilizarse para prevenir el fracaso escolar, y facilitar aprendizajes académicos tan importantes como leer y escribir (Solano Córdoba, 2013). Una escuela que desestima tales indagaciones y experiencias infantiles hasta el extremo de pretender enseñar todo a la niñez sobre aquellas tecnologías, sin la más mínima consideración hacia sus hipótesis, ideas, percepciones y experiencias al respecto, es una escuela que se mata a sí misma.

\section{Declaración de Material complementario}

Este artículo tiene disponible, como material complementario:

-La versión preprint del artículo en https://doi.org/10.5281/zenodo.3765407

\section{Referencias}

Bauman, Z. (2007). Vida de consumo. Fondo de Cultura Económica.

Bericat Alastuey, E. (2005). Sedentarismo nómada: El derecho a la movilidad y el derecho a la quietud. En de R. del Caz y M. Saravia (Eds.), El derecho a la movilidad. Informe de report of Valladolid (pp. 1320). Universidad de Valladolid, Escuela de Arquitectura. https://www.researchgate.net/profile/ Arianna Dagnino/publication/275651868 Report of Valladolid The Right to Mobility/ links/5542ab530cf23ff71683623f/Report-of-Valladolid-The-Right-to-Mobility.pdf 
http://doi.org/10.15359/ree.25-2.27

http://www.una.ac.cr/educare

educare@una.ac.cr

Buckingham, D. (2002). Crecer en la era de los medios electrónicos. Tras la muerte de la infancia. Morata.

Buckingham, D. (2008). Más allá de la tecnología. Aprendizaje infantil en la era de la cultura digital. Manantial.

Buckingham, D. (2013). La infancia materialista: Crecer en la cultura consumista. Morata.

Camargo, D. M. y Orozco, L. C. (2013). Factores asociados a la disponibilidad y uso de medios electrónicos en niños desde preescolar hasta $4^{\circ}$ grado. Biomédica, 33(2), 175-185. https:// doi.org/10.7705/biomedica.v33i2.779

Carr, N. (2018). Superficiales. ¿Qué está haciendo internet con nuestras mentes? Taurus.

Castells, M. (2012). Redes de indignación y esperanza: Los movimientos sociales en la era de internet. Alianza Editorial.

De Benito-Castanedo, J. (2017). Análisis bibliográfico sobre la brecha digital y la alfabetización en nuevas tecnologías. Revista Electrónica Educare, 21(2), 1-10. https://doi.org/10.15359/ ree.21-2.9

De Sousa Santos, B. y Meneses M. P. (Eds.). (2014). Epistemologías del Sur (Perspectivas). Akal.

Freire, P. (1970). Pedagogía del oprimido. Siglo XXI.

Giroux, H. A. (2003). La inocencia robada. Juventud, multinacionales y política cultural. Morata.

Gopnik, A. (2010). El filósofo entre pañales. Revelaciones sorprendentes sobre la mente de los niños y cómo se enfrentan a la vida. Ediciones Temas de Hoy.

Han B.-C. (2017). La expulsión de lo distinto: Percepción y comunicación en la sociedad actual. Herder.

Hidalgo Aguilera, L. (2010). La basura electrónica y la contaminación ambiental. Enfoque UTE, 1(1), 46- 61. https://doi.org/10.29019/enfoqueute.v1n1.16

Honoré, C. (2008). Bajo presión. Cómo educar a nuestros hijos en un mundo hiperexigente. RBA.

Illouz, E. (2012). ¿Por qué duele el amor? Una explicación sociológica. Clave intelectual.

Klein, N. (2011). No logo: El poder de las marcas. Paidós.

Lanier, J. (2018). Diez razones para borrar tus redes sociales de inmediato. Debate.

Marsh J. (2004). The techno-literacy practices of young children. Journal of Early Childhood Research, 2(1), 51-66. https://doi.org/10.1177/1476718X0421003 
http://doi.org/10.15359/ree.25-2.27

Martínez Alier, J. (2005). Ecologismo de los pobres. Conflictos ambientales y lenguajes de valoración. Icaria Ediciones.

Nussbaum, M. C. (2001). El cultivo de la humanidad. Una defensa clásica de la reforma en la educación liberal. Editorial Andrés Bello.

Pérez Tornero, J. M. (2008). La sociedad multipantallas: Retos para la alfabetización mediática. Comunicar, 16(31), 1525. https://doi.org/10.3916/c31-2008-01-002

Pisani, F. y Piotet, D. (2009). La alquimia de las multitudes: Cómo la web está cambiando el mundo. Paidós.

Robinson, K. H., Díaz, C. J. y Townley, C. (2019). Constructions of knowledge and childhood: Addressing current affairs with children with a focus on parents' practices and children's news. Contemporary Issues in Early Childhood, 20(4), 324-336. https://doi. org/10.1177/1463949119888483

Sánchez Blanco, C. (2013). Infancias nómadas. Educando en el derecho a la movilidad. Miño y Dávila Editores.

Sánchez Blanco, C. (2016). Tecnologías de la información y la comunicación en el aula de Educación Infantil: Críticas y desafíos. En Roig Vila, R. (Ed.), Tecnología, innovación e investigación en los procesos de enseñanza-aprendizaje (pp. 1279-1285). Octaedro.

Sánchez Blanco, C. (2017). Ordenadores en educación infantil: Voces de la infancia en Galicia (España). Revista de Pedagogía, 38(102), 31-52. http://www.redalyc.org/articulo. oa?id=65952814003

Sánchez-Blanco, C. (2018). Fuego, meteoritos y elefantes. Cruzando fronteras en educación infantil. Miño y Dávila Editores.

Solano Córdoba, O. L. (2013). El aprendizaje combinado y el desarrollo de las habilidades requeridas para la comunicación escrita. Revista Electrónica Educare, 17(3), 293-313. https://doi.org/10.15359/ree.17-3.14

Steinberg, S. R. y Kincheloe, J. L. (Comps.). (2000). Cultura infantil y multinacionales. Morata.

Tobin, J. (Ed.). (2004). Pikachu's global adventure: the rise and fall of Pokemon. Duke University Press. https://doi.org/10.1215/9780822385813-013

United Nations International Children's Emergency Fund. (2017). Estado mundial de la infancia, Niños en un mundo digital. https://www.unicef.org/spanish/publications/files/ SOWC 2017 SP.pdf 